\title{
Working in verticalized platform vessel: an ergonomic approach in the oil industry
}

\author{
Garotti, Luciano ${ }^{\mathrm{a},}{ }^{*}$ and Mascia, Fausto ${ }^{\mathrm{b}}$ \\ ${ }^{\mathrm{a}}$ CENPES-Petrobras - Rio de Janeiro, Brazil (Luciano.garotti@petrobras.com.br) \\ ${ }^{\mathrm{b}}$ Deparment of Production Engineering, University of São Paulo, Brazil (fmascia@usp.br)
}

\begin{abstract}
In this paper we point some aspects of workers activities in offshore units in the oil industry. These units became more verticalized and have a greater number of operating systems. Our goal is to present the main difficulties that workers face in these units.
\end{abstract}

Keywords: oil industry, platform vessel, work analysis,

\section{Introduction}

The discovery of major oil reserves has led to exploration and production projects with increasing operational capabilities and larger equipment used. Because of these demands, some techniques have been adopted in the design of new facilities such as grouping of similar projects in families, adoption of modular design (simultaneous development of different subsystems to reduce the runtime of the project) and vertical integration of production facilities.

From the point of view of work done in these plants, the changes are significant and can lead overload to workers. From the activity of the workers, we show in this article some results from a study that evaluate the difficulties and constraints of work due to the lack of incorporation of parameters defined in the design phases.

\section{Theoretical bases}

The modular design principle is not a new concept. It was initially adopted in the automotive industry and aligned with the adoption of techniques of rationalization of production processes [1].

According to Sako and Murray [12], the module is a basic unit of product with standardized interfaces. Some modules are combined to form a base from which it is possible to generate product variants belonging to the same family. The authors emphasize that modularization enables a greater variety of products and allows us to respond quickly to the needs of users, since it is possible to configure different products from the combination of standard components.

The concept of modularity applied to product design provides greater flexibility in designing the modules without direct dependence on other stages of the project. Due to this independence, it is possible to increase the innovation in the design process and reduces the design time of new versions [11]. Another benefit that provides modular constructive principle is to reduce the assembly time. Consequently, the product becomes available to the user in a shorter time.

The modular architecture has spread to other segments of the industry. In the oil sector, this principle has been incorporated into the design process. The project of exploration and production units, such as Floating, Production, Storage and Offloading (FPSO) vessels, began to be designed and constructed according to this principle. Some benefits can be identified: reducing design time, reduced time to begin operations, reducing the cost of the units.

Another change that comes through the FPSO vessels is the vertical integration of the facilities. This alternative is the result of a compromise on the two opposing characteristics: production capacity and area demanded for the equipment installed. That is, to meet the demands of production levels ever higher would require a larger area for equipment. However, a facility with the largest area necessarily implies a

*Corresponding author. E-mail: fmascia@usp.br 
higher cost of manufacture of the vessel. Thus, the alternative that minimizes costs is the verticalization of vessels.

From an economic standpoint, this choice seems to be a good solution. Regarding to exigencies of work that this setting can cause would be necessary to treat them in the design phases. However, few references can be founded in the literature in this field. For example, Priest [9] highlights the effects of the market, availability of capital. Slack [13] identifies the criteria for the success of a project quality, reliability, maintainability. The life cycle of the project, its sustainability, profitability of the project [6] are also considered. However, we can note few considerations in terms of ergonomics during its development. The lack of incorporation of ergonomic criteria in projects entails a series of unsatisfactory results. For example, difficulties in the startup of new plants, high rates of damage or waste, more time to reach normal operation in a process.

According to authors in the field of ergonomics, the determinants of a work situation are defined in the phases of project development. However, current practice is to consider the work to be performed later, in detail stages of project when they are already solved several aspects such as production capacity, building, technology employed. The choices are fixed on economic or technical criteria. Often, the concern with work is limited to the physical environment.

The challenge then becomes the integration of issues relating to human work before detailed studies. When the ergonomist is called by the entrepreneur at an early stage of the project, he can contribute to the enrichment of the objectives of, and even to the discussion on the principles of solutions. It is partly the same when he is integrated very early in a team proect coordinator, as states Daniellou [4].

Martin [8] in a text on architectural design is an interesting description of the contribution of ergonomics in projects. At each stage of a project the author details the participation of ergonomist and concludes a progressive change in his role changed from a local influence on the design of spaces to the consideration of work activities, from the definition of business strategies to operations.

Other examples of contributions of ergonomics to the design of workspaces can be noted. Broberg [2] describes the case of a manufacturing project that participatory ergonomics actively had contributed to in the design of workspaces. Conceição et al. [3] point out that the articulation and compatibility between the needs of different users and designers is at the origin of the innovations present in the solutions deployed in the project of an integrated control center.

Although the benefits that is provided by the integration of ergonomics in the early stages of the project, this is not a practice in design processes. The case study presented in this article shows, even partially, the difficulties that employees may face when operating equipment whose design has considered the ergonomic issues only in the final stages.

\section{Method}

In order to understand the determinants of work and its consequences for workers we adopted the approach of the ergonomic analysis of work [5 - 7]. Initially, interviews were conducted with professionals involved in the design of platforms. We look up the history of design and development methods. Ergonomic analysis reports performed in other offshore company were also consulted.

The interviews pointed to areas of a production platform that could be subject to further analysis. Discussions with stakeholders of the company led to the definition of the process area because it is a central area of production and because of the lack of ergonomic studies in the sector. The team of production operators was later defined as the focus of the research because they are directly involved in production operations for oil and gas platform.

The requirements adopted to define the platform to be studied were: interest by the project management in the incorporation of ergonomic requirements for future installations, similarity with the company's recent projects and recent installations. Thus, it was decided to study a Floating, Production, Storage and Offloading (FPSO) ship in operation since early 2005 There were two visits to the vessel, the first lasting from 3 days to carry out first observations. The second visit lasted four days to carry out systematic observations of work situations previously defined. Between the first and second visit there was an interval of 1 month.

During the first visit we interviewed industry leaders and coordinators of the platform in order to understand the overall functioning of the production. Were consulted documents and operational reports and surveys conducted on the tasks of production workers. During this period, we conducted observations of work in the production area. In this 
manner we defined the situations to be studied: cleaning and clearing of the production lines, leak testing of wells in the hydraulic unit, because it is more frequently performed tasks.

Moreover, these tasks require physical exertion and various displacements due to the positioning of valves and manual controls and require a lot of attention because of the risk involved (high pressure operation of the equipment). Later, during the second visit to the platform were carried out systematic observations of performing these tasks. In this paper, we focus on the task of clearing and cleaning of production lines (called the "pig" launch).

\section{Case study}

The platform on which the study was conducted is a FPSO type (floating, production, storage and offloading) in operation since early 2005. Its dimensions are 337 meters in length, water depth of 800 meters, 18 production wells and 11 injection wells. Its production capacity is 150,000 barrels / day to $6,000 \mathrm{~m} 3 /$ day of natural gas. The storage capacity is 1.6 million barrels of oil. The platform is designed according to principles of modular construction. The deck of the platform was divided into areas reserved for each module, including production equipment, processing and export, support for workers and equipment and offices and housing. Due to the vertical, the production modules reach up to 20 feet tall.

The organizational structure of the platform consists of three groups: management platform, technical and managerial support, operation. The operating positions are divided into four sub-groups: production (tasks directly related to extraction and processing of oil and gas); boat (processes related to the stability of the vessel in the ocean), facilities (processes for the supply of electricity, ventilation, air conditioning, refrigeration, water, water for fire fighting, other security systems), maintenance (maintenance procedures of all equipment on the platform).

Working hours are two twelve-hour shifts (7 am to $19 \mathrm{~h}-19 \mathrm{~h}$ day and $7 \mathrm{am}-$ night). The work system is shipped 14 days and 21 days off (land). There alternating work schedules. The first 7 days onboard are on the day shift, the remaining seven on the night shift. The production team consists of 9 employees per shift. They are: supervisor, P1 (2 workers) and P2, P3, P4, P5 (1 each worker), a technical and a chemical operator. The team is responsible for the following processes: production of oil, artificial lift, import and export gas production, processing waste from production, measurement, chemical injection, water injection and monitoring and control of the operation. As part of the production team, each operator is responsible for steps in the process which involves the monitoring of certain critical equipment, which are in a given area.

In the production area of the platform it is possible to categorize tasks into six groups (macro-tasks): Programming Operation, Operation, Monitoring and Verification of Conditions of Equipment, Cleaning, Maintenance Simple, Monitoring and Maintenance performed by a specialist.

All employees of the production team perform these steps. The difference between them is that each one is allocated in a specific area of the platform. Consequently, the tasks of each team member are associated with certain equipment installed in each area. The study focused on the work of the operator P3. Their tasks are:

- Check the schedule for work permits (PT) and organize its implementation. For this, the employee fill out forms in the presence of the worker that will perform the task (outsourced operator)

- Monitoring, when necessary, the work performed by outsourced operator in his area.

- Inspect the area under his responsibility and, in case of problems, communicate the supervisor by phone or email. Upon inspection the main parameters checked are the operating pressure and leaks identification.

- Prepare the launching of the pig (requires verification service wobbly).

- Provide resolution of contingencies occurring during the performance of services by outsourced operators.

- Answer requests from other production operators.

\section{Results}

Initially we will describe a typical working day of the operator P3. The sequence of actions performed by the worker himself was reported during interviews and supplemented with observations from work. Then, we highlight some points that will be deepened in order to show the work activity.

In the early morning the operator receives and checks the schedule of work permits (PTs) of the day. 
He can be informed by the night shift operator a need to issue new PT to perform service on the same day or next day; launch of pig accomplished overnight, whose receipt will be occur during the day; any other activity that will extend the evening and during the day. All tasks requires filling out forms, before it began, in the presence of the performer of the service. Once completed the emissions of PTs, the operator checks the status of P3 Hydraulic Unit (HPU) in terms of pressure, leakage and operation of the valves PSVs. Atypical situations are reported to supervisor by telephone or email. The other areas are inspected and forwarded its occurrences in the same way.

Although there is a schedule, the reality of the work of the operator P3 is very dynamic. Briefly we can say that the worker's activity is modulated by: requirement to be present in certain actions related to PTs; launch schedule of pig, and other tasks. In other words, it is necessary to establish priorities in relation to the schedule the work shift.

This tension creates a conflict for the worker: meet the requests of PTs (people external to the platform and must remain the minimum time to perform the service) and meet the demands of production among them the launch of pig with use of diesel (long time for its implementation) inspection of hydraulic fluid at HPU, and other requests. In the case of PTs, we observed that these actions vary in number and nature. This is decisive for the activity throughout the workday. There are actions that are simple, others more complex. The first require less time filling out forms for the authorization of PT, and usually do not require the presence of the worker at the site of service that will be held. Thus, the worker gives priority to completing the forms for work permits at the beginning of his shift and the remaining time for the other tasks scheduled for the shift.
On the other hand, there are scheduled tasks that require more time (general services that were never performed or more complex services). In such cases, worker often consult plans, technical drawings, equipment manuals, guidelines and discuss with workers who run the service to release the begining of service. It is also common intervention in equipment such as opening or closing of valves, isolation circuits, etc.. In addition, there are situations where the operator must follow the service from start to finish, which makes it impossible to start other tasks while the service is completed. During patrols to inspect the equipment he is often interrupted due to problems related to external services. The most common are leaks and machine downtime.

To illustrate the work of the operator P3, we describe some periods of his activity. In one of the observation period which lasted about 3 hours (14:50 to $17 \mathrm{~h} 32$ ) the worker performed the following tasks: leak test on the lines of HPU; open manually valve injection of water; monitoring of the electric pump HPU; monitoring pump injection of alcohol; monitoring and closure of PTs. During this period the worker walked 850 meters and up to higher levels (20 meters) 4 times. When performing such tasks, the operator acted in eight equipment, spread over three levels of each module.

Another example of the work of the operator P3 is the launch of Pig. On that day the operator filled forms for PTs, held injection of gas well production line and testing of hydraulic fluid leakage. The launch of the Pig was actually performed in the afternoon. However, in the morning, while doing another task (Gas injection to match well) in the area near the launch site for the pig, the employee began preparing for the operation which was scheduled for the afternoon (Figure 1) . 


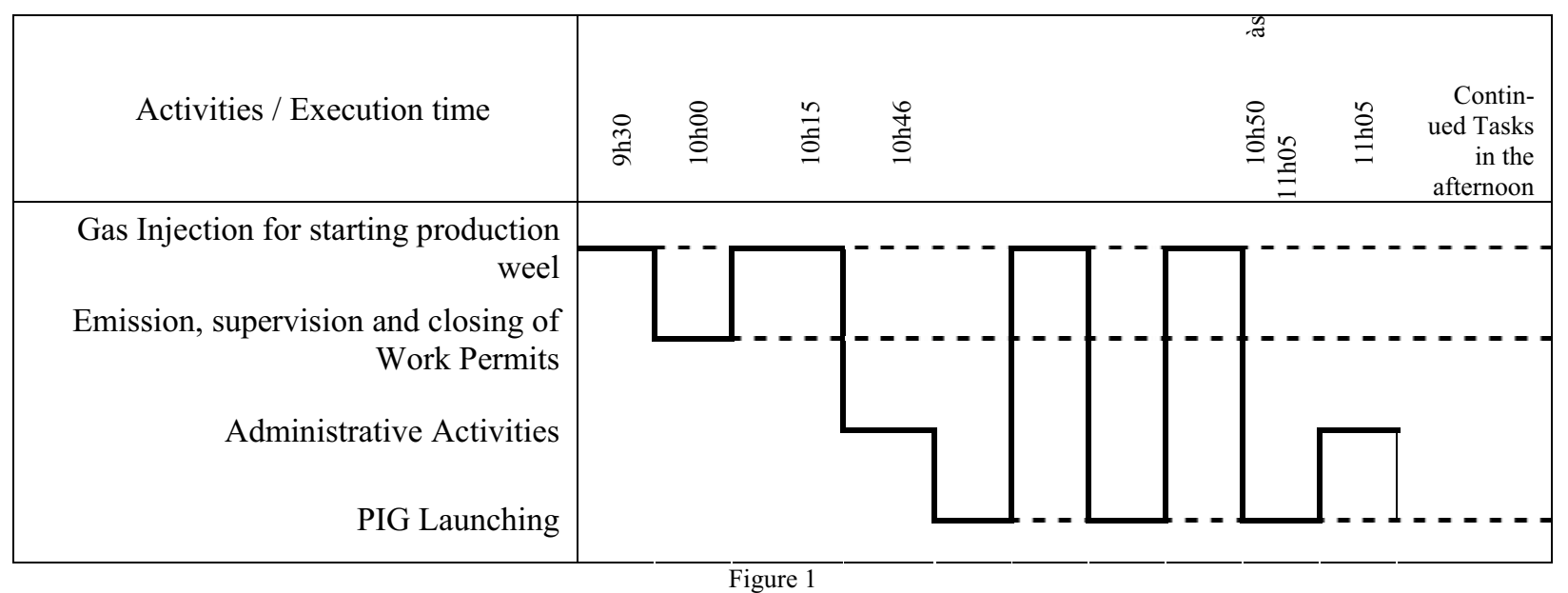

In the afternoon the operator held the launch of the Pig. This action was initiated at $13 \mathrm{hs} 47$ and completed at $17 \mathrm{hs} 35$. In this interval, the worker received a call from the control room to check for leakage of hydraulic fluid in equipment, an action that lasted about 20 minutes. To make the launch of the pig, the worker turned on the valves, made gas flow, made drainage in launching and receiving chambers. In these actions, the transition between levels was frequent, due to the location of the devices that worker should act to make the launch.

These devices are distributed between two levels of the plant (height difference of approximately 10 meters). The transition between levels is done using conventional ladder and vertical ladder. In total, 12 vertical displacements ( 6 for 6 for ascent and descent). Contingencies such as the need for special tools, interruptions to meet the control room, difficult to turn on/off the valves, check service performed by others, etc., contribute to increased displacements, at the same level (horizontal shift to go into the room control or his office), and between levels (vertical displacements up and down).

\section{Discussion and conclusions}

Activity analysis showed the requirement for significant physical effort to perform the tasks. Due to the verticalization of the platform displacements to change level are common. Often these movements are performed using the vertical ladder. A request in terms of effort may be more severe in situations where it requires the carrying of tools necessary to perform his actions on the equipment (valves). In addition to the effort required for the displacements, the technical design of the platform induces the worker to adopt extreme positions and inadequate so that it can act in an equipment (valves, flywheels), make records, etc.. Another factor that aggravates the postural requirements is the difficulty in trigger commands that are stuck, condition quite often. In these cases, the physical effort to drive its becomes even greater. An example is the alignment of valves, a routine task. These actions involves vertical displacements, due to the high number of required maneuvers and dispersion of command interfaces in the different levels of the plant.

The work analysis showed that the operator's strategy is to prioritize the production. This means that if something unexpected occurs and there is a risk to reduction of production its resolution will become a priority. In these cases the worker interrupts the ongoing activity and try to solve the problem. These events contribute to increase the displacements in searching a solution to the problem. Another strategy adopted by workers is to perform the monitoring equipment as they move within the plant. With this strategy they are able to catch up on the evolution of the production process. Depending on the experience of the worker the routes can be changed to a check on problem as he goes from one place to another.

Although we have highlighted the constraints of physical activity, it is important to emphasize the cognitive demands present in the work of of the production operators. The equipment is complex and the number of parameters to be monitored is great. Maneuvers that involve equipment require several 
actions and are recurrent. For example, to check the leak of a particular part of the process several movments of valves are carried out. The worker seeks to identify, through different combinations (opening and closing of valves), the presence of gas in the hydraulic circuits. Given the complexity of the system, act on a problem, may represent an important demand in cognitive terms to the worker. In these cases, there is an important process of construction of the problem. Knowing the system's evolution in the last hour, the technical characteristics of the device, the experience in previous situations, the employee seeks information (through inspections, displays readings, visits to the control room and colleagues) that enable him to prepare a diagnosis and a possible solution to the problem. Depending on the situation, the difficulties may increase due to the insufficient reliability of measuring and control instruments.

Another important aspect of this cognitive demand in worker activity is conducting various actions. This is due to the relatively long response time of the system. The result of an action, either on the scheduled completion of a task or solve a problem, can not be known immediately. This contributes to the switching between tasks that are not finalized. In other words, while he waits the development of an action, the worker takes up another task, and so on. In cognitive terms, this has consequences for workers who must mobilize their cognitive capacity and deal with different issues in the nature and stage of evolution. Moreover, given the characteristics of the process, a mistaken action can have serious consequences for all workers and the plant.

In general, the maneuvers are long and, with some unexpected, time of intervention on the device tends to increase. In such cases, higher the number of contingencies occurring on a journey, the less time to carry out other tasks. As a result, to complete tasks the employee has to accelerate the completion of other tasks or postpone them to the next shift.

Finally, it is important to note that the text does not explored many other situations identified in the study (including the other production workers and other sectors) and that demonstrate the difficulties that the verticalization of the plant and facilities generate for workers. Many difficulties and risk situations that workers face could be avoided if knowledge of the work activity to become part of the parameters that assist designers in the design.

\section{References}

[1] M. Blankenfelt, Managing complexity by product modularization. Thesis. (PhD). Royal Institute of Technology, Stockholm, 2001.

[2] O. Broberg, Quando o projeto participativo de espaços de trabalho se encontra com o projeto de engenharia em eventos de colaboração mútua. in: Laboreal, vol: 4, issue: 2, pages: 50 61, 2008. http://laboreal.up.pt/

[3] C. Conceição, F. Lima, F. Duarte. Ergonomics in workspace design: the integration of the needs of different users and designers. In: Odam, 2008, Guarujá, São Paulo, IX Odam, 2008.

[4] F. Daniellou A ergonomia na concepção de projetos de sistemas de trabalho. in: P. Falzon, ed. Editora Blucher, São Paulo, 2007.

[5] F. Daniellou and P. Béguin, Metodologia da ação ergonômica: abordagens do trabalho real. in: P. Falzon, ed., Editora Blucher, São Paulo, 2007.

[6] M. P. Groover, Automation, production system and computer integrated. Englewood Cliffs Prentice Hall, 1987.

[7] F. Guérin et al., Understanding and transforming work. The practice of ergonomics. Editions Anact, Lyon, 2007

[8] C. Martin, $\mathrm{O}$ ergonomista nos projetos arquitetônicos. in: $\mathrm{P}$. Falzon, ed., Editora Blucher, São Paulo, 2007.

[9] J. Priest, Engineering design for productibility and reliability. Marcel Deker, New York, 1988.

[10] S. Pugh, Total design: integrated methods for successful product engineering. Wokinghan: Addison-Wesley Publishing Company, 1991.

[11] R. Sanchez, Using modularity to manage the interactions of technical and industrial design. DMI, 2002.

[12] M.Sako and F. Murray, Modules in design. Production and use: Implications for the global automotive industry, Oxford. Said Business School, University of Oxford, 1999.

[13] N. Slack et al., Operations Management. Pitman Publishing, London, 1995. 